Revista de Comunicación y Salud, 2018, Vol. 8, no 2, pp. 51-64

Editado por Cátedra de Comunicación y Salud

ISSN: 2173-1675

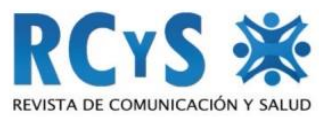

Enviado 28 de septiembre de 2018

Aprobado 30 de octubre de 2018

\title{
EL DENGUE: SU ENFOQUE COMUNICATIVO, ACIERTOS Y DESAFIOS
}

\author{
Dengue: communicative approach, accesses and challengues \\ Luisa María Guerra Rubio ${ }^{1}$ \\ Universidad de La Habana. Cuba. \\ Osana Eiriz Garcia \\ Universidad de La Habana. Cuba.
}

\begin{abstract}
Resumen
La Comunicación y la Salud requieren ir ancladas, esa alianza permitirá que los procesos comunicativos puedan prevenir la enfermedad y promover la salud, aspectos dirigidos a alcanzar el bienestar biopsicosocial del hombre en su entorno, el cual en ocasiones, puede ser hospedero de enfermedades virales trasmisibles que constituyen una amenaza para la vida. Entre estas enfermedades se distingue el dengue, por ser un problema de salud creciente en el mundo, especialmente en las Américas y su principal vector, el mosquito Aedes aegypti, ampliamente estacionado en el continente. Cuba a pesar de ser un país que exhibe resultados en Salud, Educación y Cultura distinguibles por sus logros, no escapa de su alcance. El presente ensayo realiza reflexiones que parten del análisis de estrategias, campañas y productos comunicativos empleados en la isla caribeña con vistas a atenuar la enfermedad, sus aciertos y desaciertos. Se destaca la importancia de las actitudes como eje vertebrador de la higiene ambiental como una de las variables que deben jerarquizarse para mitigar su reiterada incidencia en el país.
\end{abstract}

Palabras clave: comunicación y salud, dengue, estrategias de comunicación, actitudes pro ambientales, comunicación para el cambio social.

\begin{abstract}
Communication and Health require to be anchored, this alliance will allow that communicative processes can avoid diseases and promote health, aspects directed to get the bio psychosocial wellness of human's environment, which sometimes it can be susceptible to viral and contagious diseases that constitute a threat for life. Around these diseases dengue is distinguished, due to it is a growing health problem in the world, especially in Americas and its principal vector, Aedes aegypti mosquito, it is located in the continent widely. Despite Cuba is a country which shows results in Health, Education and Culture, it is distinguishable because of its challenges, scape from its scope. This essay makes reflections that are from the strategy analysis, campaigns and communicative products used in the Caribbean isle to face the disease, its pros and cons. It is vital to focus on the importance of attitudes as a
\end{abstract}

\footnotetext{
${ }^{1}$ Autora para correspondencia: Luisa María Guerra Rubio, luisa@fcom.uh.cu
} 
vertebral axis of environmental hygiene as one of the variable that has to rank to face its continuous country incidence.

Keywords: communication and health, dengue, communicative strategies, pro environmental attitudes, communication for social change.

\section{Cómo citar el artículo}

Guerra Rubio, L. M. y Eiriz García, O. (2018). El dengue: su enfoque comunicativo, aciertos y desafíos. Revista de Comunicación y Salud, 8(2), 51-64.

doi: http://doi.org/10.35669/revistadecomunicacionysalud.2018.8(2).51-64

\section{INTRODUCCIÓN}

El desarrollo de la comunicación para la salud ha estado asociado a las evidencias científicas sobre sus ventajas en la educación sanitaria, su antecedente más inmediato. Ha devenido en ello la influencia que han tenido los medios de comunicación como instrumentos de promoción y prevención de enfermedades y su impacto en las conductas de riesgo ante las enfermedades. Resulta importante su contribución en la consolidación de estrategias de participación en salud; así como la participación de actores y sectores sociales para garantizar el éxito de los programas de salud (Del Pino, 2010).

Según Beltrán (2010), la comunicación en salud implica desarrollar estrategias de comunicación, como un conjunto de prescripciones direccionales y procedimentales de tal manera que se afirmen los fines de estas estrategias dirigidas a la prevención como una de sus aristas más importantes.

De manera que el uso de estrategias de comunicación, servirá además para informar e influenciar decisiones individuales y comunitarias dirigidas tanto a la prevención como a la promoción de salud. La comunicación es reconocida como un elemento necesario en los esfuerzos para mejorar la salud pública y el conocimiento de cómo prevenir las enfermedades y conocer acerca de ellas; incluye también los estudios que analizan la importancia de las relaciones médico-paciente, la adherencia del individuo a recomendaciones clínicas y regímenes terapéuticos, la construcción de mensajes y campañas de salud pública en conjunto con la diseminación de información concerniente a riesgos que abrazan a las poblaciones o Comunicación en Riesgo. Se distingue igualmente el papel de la Comunicación en la promoción de salud mediante la exposición de mensajes y la búsqueda por parte del individuo de información, la utilización de imágenes en los medios masivos de comunicación, en función de educar a los consumidores acerca de cómo ganar acceso a los sistemas de salud pública y cómo cuidar su salud (Mosquera, 2003).

El sistema de salud cubano es universal, gratuito, accesible, regionalizado e integral. Gracias a los programas de salud ejecutados, se han erradicado enfermedades como el tétanos, el paludismo, la tos-ferina, la meningoencefalitis, la posparotiditis, la rubéola, el sarampión y la difteria, y constituye un gran desafío la erradicación del dengue. Los principios básicos en los que se basa la prevención del dengue en Cuba se identifican con: la voluntad política, una efectiva coordinación intersectorial, una activa participación de la comunidad y la aplicación correcta de la legislación sanitaria. (Lemos, 2006, p. 6). 
El escenario epidemiológico contemporáneo en Latinoamérica y en especial en nuestro país, se caracteriza por la existencia de varias arbovirosis, enfermedades virales trasmitidas por un vector común "el mosquito Aedes aegypi". Dentro de este grupo se identifica con mayor frecuencia en la isla, el dengue.

El dengue se ha considerado la arbovirosis de mayor importancia debido a la frecuencia de aparición, distribución, prevalencia y número de muertes que ocasiona (Murray et al., 2013). El vector principal del dengue es el mosquito Aedes aegypti. El virus se transmite a los seres humanos por la picadura de mosquitos hembras infectadas. Tras un período de incubación del virus que dura entre 4 y 10 días, un mosquito infectado puede transmitir el agente patógeno durante toda su vida.

La importancia del enfoque comunicativo en Salud y sus diversas formas de expresión en relación con el dengue como enfermedad viral nociva, se origina en sus procesos y productos que pueden contribuir a mantener a la población informada sobre las características del virus, y también proveer toda la información tanto a pacientes que poseen la enfermedad como a los que se encuentran en riesgo de contraerla, aspecto que compete a la Comunicación en términos de prevención y promoción.

En el ensayo que presentamos, se reflexiona en las diferentes alternativas utilizadas en estrategias y productos comunicativos contextualizadas en Cuba. En la actualidad las instituciones afines a este problema de salud trabajan de manera conjunta en la búsqueda de soluciones, alternativas y estrategias de comunicación que contribuyan a promover participación en las comunidades en que concurren las variables que despiertan los focos de la enfermedad y que requieren del control del vector. No obstante, a pesar de los esfuerzos que se destinan por el estado y en especial por la Dirección Nacional de Salud Pública en Cuba, en el país prevalece la enfermedad, ello devela la importancia de repensar el proceder en que la Comunicación intenta sensibilizar a la población en la búsqueda de alternativas sostenibles en el tiempo y no acotadas en intervalos de intervención.

\subsection{El dengue: Reiteraciones en su aparición}

El Dengue constituye un problema de salud creciente en el mundo, especialmente en las Américas.

Las altas temperaturas existentes en Cuba, el comportamiento de las Iluvias, la proliferación de los depósitos de basura en la comunidad, así como la baja percepción de riesgo de la población al poseer actitudes higiénico sanitarias nocivas al medio ambiente, son entre otras las causas fundamentales para que ocurra la infestación por el mosquito Aedes aegypti, que es el agente trasmisor del "Dengue, Zika, chikungunya y fiebre amarilla"; enfermedades virales que ponen en riesgo la salud. Especialistas de nuestro país vinculados a la epidemiología, apuntan además el deterioro de los programas de control del vector, la carencia de insecticidas con buena relación de costo/efectividad y la falta de educación sanitaria como algunos de los factores relacionados con la diseminación del Aedes aegypti y el incremento en la circulación de los serotipos del virus (Hoyos, 2011). 
El mosquito Aedes aegypti vive en hábitats urbanos y se reproduce principalmente en recipientes artificiales. A diferencia de otros mosquitos, se alimenta durante el día; los períodos en que se intensifican las picaduras son el principio de la mañana y el atardecer, antes de que oscurezca. En cada período de alimentación, el mosquito hembra pica a muchas personas. Los huevos de Aedes pueden permanecer secos en sus lugares de cría durante más de un año y eclosionar al entrar en contacto con el agua, este hecho nos indica que su prevalencia es muy larga. Se debe sospechar que una persona padece dengue cuando una fiebre elevada $\left(40^{\circ} \mathrm{C}\right)$ se acompaña de los síntomas siguientes: dolor de cabeza muy intenso, dolor detrás de los globos oculares, dolores musculares y articulares, náuseas, vómitos, agrandamiento de ganglios linfáticos o salpullido. Los síntomas se presentan al cabo de un período de incubación de 4 a 10 días después de la picadura de un mosquito infectado y por lo común duran entre 2 y 7 días.

La primera epidemia de Dengue Clásico en Las Américas, documentada por laboratorio, estuvo asociada con el serotipo dengue-3 y afectó a casi toda la cuenca del Caribe (Hoyos, 2011, p. 500).

Anterior a los años de la década del 70, solo nueve países habían sufrido epidemias de dengue grave. Ahora, la enfermedad es endémica en más de 100 países de las regiones de África, las Américas, el Mediterráneo Oriental, Asia Sudoriental y el Pacífico Occidental. Las regiones más gravemente afectadas son las Américas, Asia Sudoriental y el Pacífico Occidental.

Cuba a pesar de poseer un Sistema de Salud en que predomina el trabajo de promoción y prevención de salud, se ve afectada a los largo de toda la isla caribeña por focos que pueden variar anualmente en la aparición del dengue o el Sika, ambas amenazadoras del equilibrio psicosocial de su población.

Desde el enfoque comunicativo se han realizado diversas estrategias y se distinguen por elaborar propuestas para la capacitación y la participación comunitaria como formas que conducen a la mejora. Se destacan los talleres diseñados y coordinados por especialistas del Instituto de Medicina Tropical Pedro Kouri (2008), de La Habana, en su contribución a preparar al personal de salud para promover la participación comunitaria en la prevención del dengue. En este caso la estrategia empleada permitió reducir el nivel de infestación con el mosquito vector, mediante el aumento de la participación de la comunidad en la toma de decisiones, el fortalecimiento de las competencias de los equipos médicos y de los Grupos de trabajo comunitario para liderar procesos participativos en sus comunidades y la elevación de la confianza de los miembros de la comunidad en sus posibilidades de llevar a cabo transformaciones con recursos propios y apoyo intersectorial.

En el mismo sentido se ha creado una estrategia nacional de comunicación integrada por acciones de prevención y control. La estrategia incluye la producción de materiales impresos, audiovisuales, el desarrollo de charlas educativas y audiencias sanitarias, su objetivo central se encuentra dirigido a fomentar la participación colaborativa y movilizadora, de diferentes sectores y actores sociales (MINSAP, 2013). 
Experiencias de estrategias similares dirigidas a la capacitación se llevaron a cabo en otras regiones del país como Estrategia de intervención sobre Dengue en Camagüey (2010). Los resultados evidencian el conocimiento logrado por los participantes al final de la intervención, en que los encuestados podían responder a interrogantes como: ¿Qué es el dengue? ¿Cuál es el vector que lo transmite?, ¿Dónde vive, cuáles son sus hábitos?; ¿Cuál es la vía de transmisión, los síntomas de esta enfermedad y las medidas a tomar para protegernos?

En el trascurso del presente siglo en el país, se han logrado vencer los brotes de Dengue, pero sin lugar a dudas prevalece en el entorno, lo atestiguan diferentes registros de existencia de la virosis, que a veces no logran ser tan objetivos de manera numérica porque a diferencia de los resultados de diagnósticos anteriores, en la actualidad la mayoría de la población por diferentes canales de comunicación, conoce las manifestaciones de la enfermedad y cómo evitar la reproducción del vector; gracias a las campañas televisivas y radiales, prensa escrita, audiencias sanitarias, entre otros, la población ha ganado en conocimiento sobre esta fatal virosis, sin embargo no ha crecido en tomar conciencia de la percepción del riesgo de la enfermedad en sus vidas y en ocasiones no asiste a los servicios de salud porque cree sabe cuidarse durante la enfermedad y no desea internarse en un centro hospitalario, poniendo de esta manera en riesgo su vida.

La cultura en temas relacionados con salud de la población cubana, y en relación con el dengue es diferente al resto de otros países de Latinoamérica. El nivel de conocimiento de cómo prevenir y las medidas higiénico sanitarias recomendadas, así como los síntomas de la enfermedad constituyen mensajes reiterados a través de las diferentes mediaciones que posee la población; no obstante desde nuestra mirada resulta insuficiente para erradicar el dengue el conocimiento; se requiere la Comunicación para el Cambio Social; se necesitan estrategias de comunicación en los diferentes policlínicos como unidades de salud que agrupan los consultorios médicos y que a su vez, puedan conectarse a la vecindad no solo a través de información 0 audiencias sanitarias, que en gran parte de sus contenidos la comunidad conoce; se requiere que se perciba la participación tomada de la mano con la legislación y control de las actitudes sanitarias negativas, aspecto que constituye un problema no resuelto y que promueve su reaparición reiterada en épocas en que el clima resulta más favorable para ello.

\section{MEDIOS Y MEDIACIONES}

Los medios de comunicación en cualquier sociedad están imbricados con el sistema social en su condición de actores políticos encargados de la producción y reproducción de la ideología imperante. Como es reconocido, los sistemas de medios forman parte del sistema político de la sociedad y contribuyen de modo directo a su legitimación (Martín, 1993).

Las transformaciones en la comunicación pública y el cambio de la sociedad es uno de los puntos de partida analizados por Manuel Martín Serrano, teórico e investigador en la comunicación, que lo ubica como uno de los supuestos de su Teoría Social de la Comunicación. Para Martín (1993), tanto los sistemas sociales como los de comunicación pública están soportados por un equipamiento tecnológico, requieren de algún tipo de operaciones con los recursos y las personas,

Revista de Comunicación y Salud, 2018, Vol. 8, n 2, pp. 51-64 
y además implican elecciones entre los conocimientos, las creencias y los valores disponibles; estos tres órdenes corresponden a dos grandes sistemas que no siempre están coordinados entre sí: el sistema social y el sistema de comunicación pública. Por ello ubica como una categoría central a la mediación, la que asume como la productora de modelos de ajuste que operan con los recursos, las prácticas y los fines para reducir las contradicciones entre sistemas sociales y sistemas de comunicación. Dicho de otra forma: la mediación produce modelos de ajuste social y la teoría de la mediación social ayuda a comprender cómo se llevan a cabo los mecanismos de ajuste en el Sistema Social facilitando su producción y reproducción, ayudando así mismo a determinar el grado de rigidez o de elasticidad del organismo social, su vulnerabilidad o fortaleza. Las mediaciones como instancia que modula las contradicciones entre sistema social y sistema de comunicación pública, resulta uno de los aportes fundamentales de Martín Serrano por el nivel de generalidad que permite, y además su elaboración de la mediación como elemento que impone límites a lo que puede ser dicho, y a las formas de decirlo, por medio de un sistema de orden.

En Cuba según datos aportados por Herrera (2017) a partir del 1ro de enero de 1959, junto a profundos cambios de la sociedad cubana, se intervienen y nacionalizan todos los medios de difusión masiva -en unos casos para evitar que los mensajes del nuevo gobierno fueran distorsionados o manipulados y en otros porque su estructura comercial, sustentada por los patrocinios y publicidades, se debilitó con la nacionalización de las principales empresas que sostenían a las emisoras y debían depender íntegramente del presupuesto del Estado- y se modifica la función social de la televisión. El 24 de mayo de 1962, mediante la Ley 1030 del Consejo de Ministros de Cuba, los servicios radiales y televisivos pasan a integrar el Instituto Cubano de Radiodifusión, con el objetivo de difundir y orientar las emisiones a todo el territorio nacional. Para 1976 esta entidad se convierte en el Instituto Cubano de Radio y Televisión (ICRT), como organismo de la administración central del estado. Es así como hasta la actualidad, todos los mensajes van a provenir del mismo emisor -el Estado- y a responder a la misma ideología y objetivos políticos, culturales, educativos e informativos. Dentro del organismo y siguiendo esta proyección, la Televisión Cubana se convierte en un servicio público, lo que va a determinar la filosofía de sus transmisiones. Comienzan a aumentar los por cientos de programas educacionales y culturales, en su gran mayoría de factura nacional y se va a dedicar a mostrar los logros y avances de la sociedad y a representar la vida social y sus intereses, llegando a todos los rincones del país, sin tener en cuenta 0 priorizar unas zonas sobre otras por razones comerciales o políticas (Herrera, 2015).

El modelo de comunicación difusionista encuentra su espacio central en la difusión de la información a través de los medios masivos; sin lugar a dudas, estos han tenido un lugar importante en la promoción y prevención de salud. En Cuba la radio, la prensa escrita y la televisión, asumen un papel crucial en la comunicación para la salud; ya en nuestros días "Internet" también contribuye con mayor intensidad a brindar información sobre las temáticas de salud.

La prensa escrita permite trasmitir información de manera extensa y tiene seguidores sobre todo en públicos como los adultos; en nuestro país tiene un papel destacado en brindar información sobre todo en prensa local en que se reflejan los estados generales de la región y se hacen las alertas de informaciones necesarias 
sobre diversos acontecimientos, entre ellos los que destacan las problemáticas que aquejan a la población en torno a las enfermedades de alto riesgo.

En la actualidad gran parte de estos medios impresos tienen su visibilidad en internet, aspecto que permite la participación de usuarios en opiniones y preguntas sobre temas que le permiten acceder a numerosas informaciones. Sin lugar a dudas es el medio que más difunde información vinculada a la salud, y dispone de espacios de participación con el gran inconveniente que no todos los usuarios poseen la preparación necesaria para diferenciar la procedencia de sus contenidos, que no siempre pueden ser científicos en el caso de la salud y que no todos los grupos etarios acceden para poder participar con preguntas y experiencias vividas en torno a la enfermedad.

Los medios de comunicación en general brindan información y en especial la televisión, tiene la posibilidad de atrapar con sus mensajes e imágenes a quien se acostumbra a ser fiel receptor de ella. En Cuba constituye una práctica frecuente que en los horarios que suceden a espacios de novelas, y espacios noticiosos, los mensajes educativos enlacen la programación y se brinde información que ayude a las diferentes audiencias a obtener conocimientos en temas relacionados con la salud.

Los mensajes de educación para la salud, se transmiten a la población mediante spots publicitarios sobre información sanitaria, campañas de bien público, sesiones de discusión, documentales, programas específicos de educación para la salud, dirigidos a diferentes públicos metas. Estos enlazan fuertemente la comunicación y la educación que requieren las personas para fortalecer sus conocimientos y reflexionar sobre determinados temas y actitudes inadecuadas que pueden afectar el entorno.

Las imágenes utilizadas se encuentran directamente relacionadas con la cultura en salud que posee la población, se utilizan de manera reiterada imágenes de procederes adecuados, de la importancia de prevenir la existencia del vector y de la sintomatología del dengue.

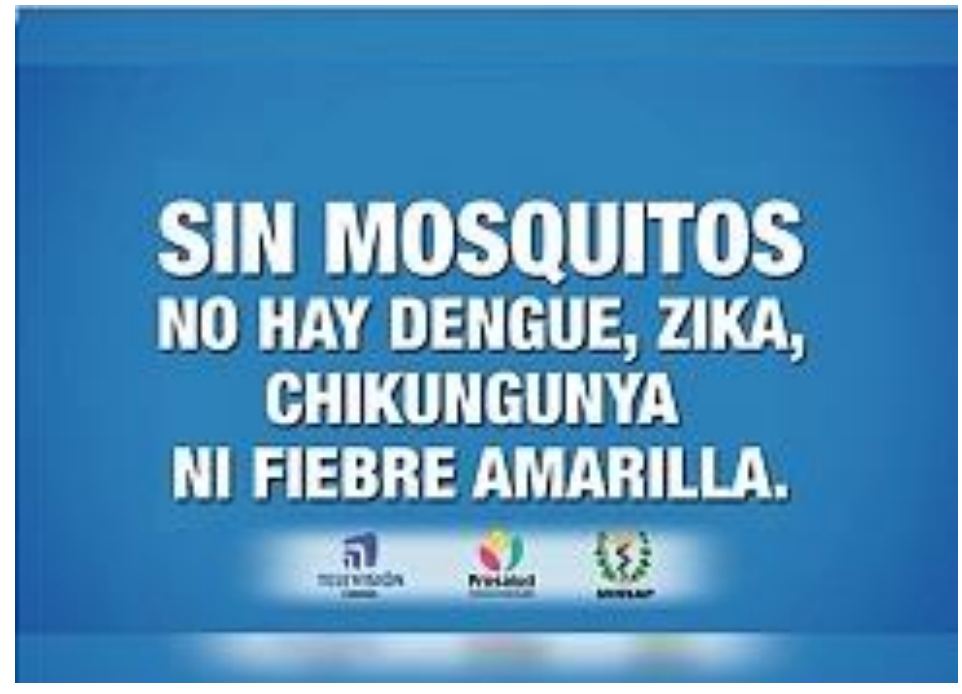

Figura 1. Imagen de spot del canal Cubavisión. Cuba.

Revista de Comunicación y Salud, 2018, Vol. 8, nº 2, pp. 51-64 
La comunicación como la "transmisión de mensajes", representa el esquema mecánico, impersonalizado, que se impone a los procesos socioculturales. Según, (Fuentes, 2013, p. 4) "Es pensar el mundo sin sujetos, es reducir a los individuos a engranajes de una maquinaria en la que sólo deben obedecer lo que se les ordena, asimilar lo que se les impone, responder a lo que se les pregunta, y acatar ese estado de cosas como si fuera natural". A pesar de esta intención educativa, basada en el conductismo, tienen aciertos al nivel de conocer. No obstante las decisiones que toma cada persona son diferentes, así como el grado de atención que prestan a estos espacios que constituyen un acercamiento a modelar la conducta de lo que debe hacerse y que independientemente de su calidad y comprensión en la relación imagen-texto, en ocasiones limitan el pensar de las audiencias a construir sus propios mensajes para prevenir conductas negativas.

Los resultados obtenidos evidencian la necesidad de contribuir a que las acciones trasciendan el carácter instrumental de la comunicación para consolidarse como un proceso de carácter social que promueva el reconocimiento, el encuentro y el diálogo de los diversos saberes (Mosquera, 2003); fomentar procesos comunicativos en salud en el que todos los grupos, comunidades y sectores de la sociedad tengan el derecho de participar y de actuar como emisores y receptores indistintamente (Kaplún, 1998). Los alcances de estas aspiraciones en la comunicación son destacables pero la participación de las audiencias en el proceso como emisores, resultan en la isla caribeña aún insuficientes.

\subsection{La comunicación para el cambio social}

El modelo de Comunicación para el Cambio Social describe un proceso donde el "diálogo de la comunidad y la acción colectiva trabajan en conjunto para producir cambios sociales en una comunidad que mejoren el estado de salud y de bienestar de todos sus miembros" (Mosquera, 2003, p. 7).

El cambio social implica la participación de la comunidad en todos los procesos concernientes a la implementación de proyectos para la salud. Asimismo, la horizontalidad de la comunicación ejerce un papel fundamental para que la población adopte como suyos, los métodos y los estilos de vida necesarios para su sostenibilidad (Mosquera, 2003).

El aporte de evidencias desde el campo comunitario, es esencial para la articulación de las acciones de comunicación, participación, comunicación, promoción y educación para la salud, así como en los programas de prevención de diferentes enfermedades (Hernández, 2017).

De acuerdo con planteamientos de la Organización Panamericana de la salud (OPS, 2011), se requiere del intercambio, la participación, y la socialización de las experiencias de los actores claves para que el desarrollo de este proceso tenga un impacto adecuado en el cambio conductual y en la trasformación social.

En la actualidad, se considera la comunicación participativa como elemento imprescindible para la toma de decisiones de los sujetos afectados por determinadas problemáticas vinculadas al cuidado e higiene del medio ambiente en la prevención de salud. Constituye una condición necesaria para la efectividad de los programas 
de intervención higiénico-sanitarios, las estrategias comunicativas y las campañas de comunicación orientadas hacia el cambio de actitudes y comportamientos. La participación activa de la comunidad o institución afectada, demanda la participación en el diagnóstico de los problemas que subyacen y en las propuestas de solución de las mismas, de esta manera se logra un acercamiento cultural y afectivo en los procesos comunicativos de los agentes que requieren del cambio y los que reconocen su necesidad.

Es por ello que el proceso de comunicación horizontal juega un papel esencial para posibilitar la participación de la comunidad de una manera igualitaria en la toma de decisiones de los problemas que afectan sus dinámicas cotidianas y las amenazas que dañan su entorno físico ambiental para poder prevenir los elementos causantes de diferentes epidemias.

La creación de un escenario de participación comunitaria, "promueve la producción, retroalimentación y adecuación de los mensajes a las particularidades de cada contexto y movilización de diferentes actores sociales (Hernández, 2017, p. 28).

Experiencias en la ciudad de la Habana aplicadas en intervalos de 2 años de sistematicidad, permitieron reducir el nivel de infestación con el mosquito vector mediante el aumento de la participación de la comunidad en la toma de decisiones, el fortalecimiento de las competencias de los equipos médicos y de los grupos de trabajo comunitario para liderar procesos participativos en sus comunidades y la elevación de la confianza de los miembros de la comunidad en sus posibilidades de llevar a cabo transformaciones con recursos propios y apoyo intersectorial (Sánchez, Pérez, et.al., 2008).

Un estudio realizado en el municipio del Cotorro, Habana, Cuba, informa que aunque la población tiene conocimientos sobre el dengue y conoce las medidas para evitar los criaderos del mosquito, mantienen comportamientos y prácticas inadecuadas, fundamentalmente en los exteriores de la vivienda (Bombino, 2006).

En correspondencia con estas ideas nos pronunciamos a favor de lo planteado por (Hoyos, 2011) entre las causas fundamentales de la ruptura entre el conocimiento y la práctica se distingue que: La población no valora el riesgo de enfermar de dengue y le restan importancia a las medidas para eliminar los criaderos, no han modificado los hábitos, costumbres y actitudes asociados a las prácticas de prevención y eliminación de los criaderos del Aedes aegypti,no tienen conciencia de la magnitud del problema y no tienen sentido de permanencia comunitaria.

Rebellato (2000) establece tres niveles de participación en función de la implicación de los sujetos en un determinado proceso: formar parte, tener parte y tomar parte. Según este autor, la idea de participación se completa con este último nivel donde los protagonistas están completamente incluidos en el proceso de toma de decisiones, y son los encargados de planificar y realizar las acciones, lo que sustenta un sentido de pertenencia y concientización con el proyecto de cambio del que son partícipes; desde nuestra mirada sucede que una vez la estrategia o la intervención culminan, el tiempo se encarga de que la dinámica realidad repliegue 
las acciones que en un tiempo limitado lograron un cambio; la práctica mucho más rica y relativa que la teoría, demuestra que los problemas concurren nuevamente, una vez finalizado el proyecto o intervención, no siempre se planifican acciones o cortes en el tiempo, lo cual significa que la intervención no logra consolidar buenas prácticas; las actitudes necesarias para lograr conductas estables en los ciudadanos, requieren de una estabilidad de negociación en el tiempo, de coordinaciones entre los diferentes sectores de la población desde todas las instituciones no sólo las de salud y que los significados compartidos sobre la prevención del dengue sean los mismos.

Se demanda mayor participación de la Comunicación Social en la articulación de los procesos comunicativos de los sectores que pueden implicarse para respuestas eficaces ante un problema que exige respuestas integradoras.

\subsection{Las actitudes en el dengue: su eje vertebrador}

El desarrollo de actitudes se ubica en el eje de los objetivos a lograr en la relación Educación Comunicación y Salud. La actitud se forma y se aprende en el proceso de desarrollo, constituyendo uno de los componentes psicológicos estables de la personalidad que influye en el comportamiento ante determinado objeto o situación.

En etapas muy tempranas de la vida, en la niñez, y en especial desde la etapa escolar, se aprecia en ese grupo etario, una marcada curiosidad por la naturaleza, por lo que debemos aprovechar ese interés para contribuir a la formación de actitudes a favor de lo ecológico y la responsabilidad social de la salud individual y hacia la higiene ambiental desde las instituciones escolares y la familia. En dichas instituciones se comienza a cultivar y sistematizar los conocimientos, fomentando un pensamiento crítico e innovador para la transformación de la realidad mediante el desarrollo de habilidades, formación de valores para analizar los conflictos, investigar las causas y buscar soluciones que posibiliten la intervención individual y comunitaria y la comprensión sobre los problemas ambientales.

Es evidente que una de las causas de la degradación ambiental y las consecuencias negativas para la salud humana está ligada a la actitud, incluyéndose las indisciplinas, negligencias y otras actitudes que tienen un carácter plenamente subjetivo propio de la conducta humana.

Algunos autores como Holahan (2002), insisten en la importancia de la actitud en el estudio del medio ambiente, partiendo del supuesto teórico de que ésta ayuda a las personas para tomar decisiones relacionadas con el uso y el cuidado del entorno físico, así demostrando el estrecho vínculo entre la actitud y el comportamiento humano.

Al respecto, González (1989) concibe las actitudes como la forma organizada y estable ante las situaciones $u$ otras personas concretas mediante su sistema integral de expresión, que incluye tanto sus comportamientos, como su sistema de valoraciones y expresión emocional; la actitud es una predisposición ante determinado objeto o conducta, y también es la que mediatiza el comportamiento interactuando otras estructuras de la personalidad, con lo cual observamos la relación estrecha entre la actitud y la conducta. 
En la formación de actitudes, se destaca la importancia de lo social, abogando la decisiva influencia del mismo sobre la actitud. Uno de los autores que asume este postulado es Vigotsky, planteando la concepción del condicionamiento social como: "todas las funciones superiores no se formaron en la biología, en la historia de la filogénesis pura, sino que el mecanismo mismo que se encuentra en la base de las funciones superiores es un calco de lo social" (1987, p. 31).

Coincidiendo con los planteamientos anteriores, Casales expresa:

Las actitudes se forman y se desarrollan a lo largo de la vida del individuo, condicionadas por el contexto social al cual están expuestas en dependencia de los grupos a que pertenecen, los cuales se estructuran de acuerdo al sistema de valores predominantes en la sociedad. Por ello cada sociedad estimula y desarrolla determinado tipo de actitud en correspondencia con su estructura socioeconómica (1989, p. 162).

Las actitudes no se adquieren sólo como un producto de nuestra interacción individual con otros objetos y personas, sino que se adquieren como consecuencia de nuestra pertenencia a ciertos grupos sociales, porque es un proceso progresivo e influyen las creencias, las normas que se otorgan ante las diferentes situaciones, y la postura que tomamos ante ellas. A tono con estas definiciones, Marimon (2004) caracteriza las actitudes en los siguientes términos: son estructuras psicológicas, derivadas del aprendizaje y de la experiencia del individuo; se forman como resultado de la actividad del individuo. Independientemente de que las actitudes se forman como resultado de la actividad, se modifican y condicionan en la actividad subsiguiente; tienen la propiedad de reflejarse en el comportamiento, el sistema de valoraciones y expresión emocional. La manera en que se expresan no solo depende del objeto en cuestión, sino también de las normas grupales. Además existe una unidad sistémica entre los componentes cognitivos, afectivos y conductuales que en definitiva configurarán nuestras actitudes. En general, la formación de actitudes está altamente relacionada con la experiencia personal y social que cada individuo vive. Las teorías de aprendizaje social entre las que se destaca la representada por Bandura, destacan que gran parte de lo que aprendemos se aprende por observación de los otros.

La actitud hacia una conducta determinada es el resultado de la creencia de que la acción conduce a unos resultados concretos y la evaluación de esos resultados; "la norma subjetiva surge a partir de las creencias acerca de lo que las demás personas piensan que se debe hacer" (Guerra, 2011, p. 29). La intención predice la conducta y depende, por un lado, de las creencias del sujeto acerca de las consecuencias que una determinada conducta pueda generar o creencias conductuales, que determinan la "actitud del sujeto sobre la conducta" en cuestión (Guerra, 2011, p. 28); por otro lado, la intención conductual también depende de la importancia de las creencias del sujeto hacia otros individuos o creencias normativas y de la percepción que éste tenga de las presiones que la sociedad ejerce sobre él en relación con la conducta o normas subjetivas; por ello la presencia de factores que puedan facilitar o impedir la ejecución de un comportamiento o creencias sobre el control, sobre su propia capacidad de realizar un comportamiento resulta necesaria.

Finalmente por todas las ideas expuestas se puede inferir que las actitudes constituyen aprendizajes estables y, dado que son aprendidas, son susceptibles de

Revista de Comunicación y Salud, 2018, Vol. 8, oㅡ 2, pp. 51-64 
ser fomentadas, reorientadas e incluso cambiadas; en una palabra, enseñadas. Ellas están íntimamente ligadas con la conducta, pero no son la conducta misma. De estas ideas se desprende la importancia que tiene en la prevención del dengue el conocimiento, pero el actuar en correspondencia con el mismo, depende de las actitudes que logremos pautar a un nivel social.

\section{REFLEXIONES FINALES}

Para concluir, nos parece oportuno reconocer el esfuerzo dialógico existente entre el Sistema Social en el país y las mediaciones sociales a tono con la necesidad de erradicar el dengue; desde la comunicación se hace necesario fortalecer las acciones existentes en los medios de comunicación empleados y los productos comunicativos para su prevención, marcadas aún por un enfoque difusionista; en el campo de la comunicación aún predomina el abordaje vertical donde existe un polo generador de decisiones o mensajes, y por otra parte un polo receptor, aparentemente pasivo ante los mensajes que recepciona.

Se requieren de enfoques más abiertos a la participación; se necesita de un pensamiento integrador para realizar cambios y que los mensajes estimulen el pensar, que a pesar de dar conocimientos y sugerencias conductuales, permitan el análisis del receptor que reclama de la participación. Las prácticas sociales son acciones reflexionadas entre interlocutores que colectivamente producen sentidos a su comunicación y confieren significados a su acción, a su agencia. Y dado que las prácticas no se despliegan en el vacío social e histórico, según Orozco "el desafío aquí, entonces, es crear, ampliar y fortalecer los "escenarios para el diálogo" desde donde se revitalicen los procesos comunicativos". (1998, p. 4).

Constituye un desafío lograr un cambio en la comunicación más allá de su utilidad instrumental, para constituirse en un proceso de carácter social que posibilite el reconocimiento, encuentro y diálogo de los diversos saberes, al decir de Mosquera "poder consolidar la articulación entre los diferentes sectores sociales en torno a la salud, para generar procesos de cambio que mejoren las condiciones de bienestar de la población" (2003, p. 3).

\section{BIBLIOGRAFÍA}

Beltrán, L. (2010). Comunicación para la salud del pueblo. Estudio sobre las culturas populares, 22.

Bombino, Y. (2006). Evaluación rápida sobre el nivel de información para evitar los focos de Aedes aegypti y la percepción de riesgo de enfermar de dengueen la población del municipio Cotorro. Reporte Técnico de Vigilancia. Disponible en: http://www.sld.cu/galerias/pdf/sitios/vigilancia/bombinoago2006.pdf

Casales, J. C. (1989). Psicología social, contribución a su estudio. Ciudad de la Habana: Editorial Ciencias Sociales.

Del Pino, T. (2010). La comunicación educativa para la salud en la atención primaria. Un estudio de casos en Ciudad de la Habana. (Tesis de Maestría en Ciencia de la Comunicación). La Habana, Facultad de Comunicación Social, UH. Cuba. 
Fuentes, R. (julio de 2003). Modelos y prácticas de la educomunicación. En: Conferencia en el Encuentro Internacional Educación y comunicación. Universidad de Tijuana.

González, F. (1989). Psicología, principios y categorías. Ciudad de La Habana: Editorial Ciencias Sociales.

Guerra, L. (2011). Programa de intervención orientado a la formación de actitudes proambientales. Santa Clara. Cuba: Editorial Samuel Feijó.

Hernández, B. e Hidalgo, M. (2000). En Actitud y creencias hacia el medio ambiente. En J. I. Aragonés y M. Amérigo (Eds.), Psicología ambiental (pp. 281-288). Madrid: Ediciones Pirámide.

Hernández, Y. (2017). Gestión de Comunicación comunitaria para la prevención de arbovirosis. (Tesis de Maestría en Ciencia de la Comunicación). Facultad de Comunicación Social. Universidad de La Habana. Cuba.

Herrera, Dagmar. (2015). Propuesta de modelo de televisión local para el desarrollo de los municipios cubanos. (Tesis doctoral). Facultad de Comunicación Social. Universidad de La Habana. Cuba.

Holahan, C. (2002). Psicología Ambiental. México: Editorial Limusa.

Hoyos, R. (2011). Intervención comunitaria en el dengue como una necesidad social. Revista Cubana de Salud Pública, 37(4), 500-509.

Kaplún, M. (1998). Una pedagogía de la Comunicación. Madrid: Ediciones de la Torre.

Kourí, G. (2006). El dengue, un problema creciente de salud en las Américas. Revista Panam Salud Pública, 19,143-145.

Martín, M. (1993). La producción social de comunicación. Madrid: Alianza Editorial.

Lemos, G. (2006). El sistema de salud cubano. Estrategias para el control del dengue. Biotecnología Aplicada 23(2). Disponible en https://elfosscientiae.cigb.edu.cu/PDFs/BiotecnolApl/2006/23/2/BA002302EN13

Marimón, C. (2004). La formación de una actitud ambiental responsable en estudiante de secundaria básica. (Tesis doctoral). Instituto Superior de Pedagogía "Félix Varela". Santa Clara. Cuba.

MINSAP (2013). Programa de vigilancia y lucha antivectorial. La Habana: Encimed.

Mosquera, M. (2003). Comunicación en Salud: Conceptos, Teorías y Experiencias. Washington. D.C: OPS.

Mosquera, M; Lloyd, L. et al. (2005). El dengue en las Américas. Disponible en htpp://www.comminit.com/la/tendencias/tendencias2004/tendencias-107.html. 
OPS (2011). Sistematización de lecciones aprendidas en proyectos de comunicación para impactar en conductas. Disponible en http://iris.paho.org/xmlui/handle/123456789/33809

Murray, N. Quan, M. \& Wilder-Smith (2013). Epidemiology of dengue, paste, presente, and future prospects. Clinical epidemiology, 5, 299-309.

Orozco, G. (1998). Las prácticas en el contexto comunicativo. Revista Chasqui, 62.

Rebellato, J. (2000). Antología mínima. La Habana. Editorial Caminos.

Rodríguez, O.; Abregu, S.; Cielo, A.; Espindola, A.; et al. (2010). Estrategia de intervención sobre Dengue. Archivo Médico de Camagüey, 14(3). Disponible en http://www.redalyc.org/articulo.oa?id=211114981014

Sánchez, L.; Pérez, D.; Alfonso, L.; Castro, M.; Sánchez, L. M.; Van der Stuyft P. et al. (2008). Estrategia de educación popular para promover la participación comunitaria en la prevención del dengue en Cuba. Rev Panam Salud Pública. 24(1), 61-69.

Vygotsky, Lev. S. (1987). Historia del desarrollo de las funciones psíquicas superiores. Ciudad de la Habana: Editorial Científico Técnica. 